\title{
Chapter 24 \\ Deterrence: A Continuation \\ of Emotional Life with the Admixture of Violent Means
}

\author{
Samuel Zilincik and Isabelle Duyvesteyn
}

\section{Contents}

24.1 Introduction

24.2 Salient Themes of Contemporary Emotion Science as Reflected in Deterrence Literature

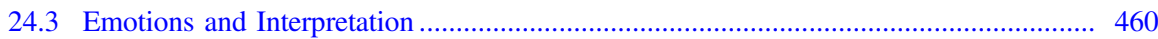

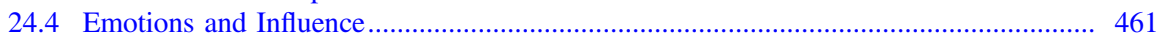

24.5 Emotions in Collectives ............................................................................................ 463

24.6 The Emotion-Centric Model of Deterrence ............................................................. 464

24.7 US-Iran Case Study ............................................................................................... 466

24.7.1 Phase 1: Emotions before Deterrence ........................................................ 466

24.7.2 Phase 2: Deterrence and the Emergence of Emotions ................................ 468

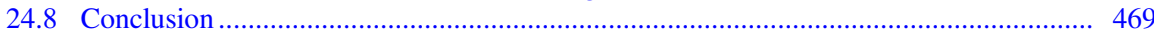

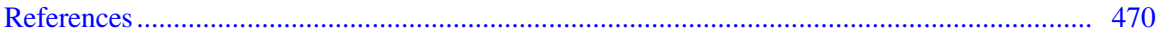

"...emotions may be slippery, but they are also by far the most salient aspect of our lives. They give meaning to everything."

De Waal 2019, 9-10

\begin{abstract}
Deterrence is more than anything a psychological mechanism. It depends on emotions that orchestrate processes across organisms to deal with the challenges of the present and the future. However, deterrence scholarship has had a turbulent relationship with emotions. The main aim of this chapter is to review what we know and what we do not know about emotions and deterrence. The secondary aim is to
\end{abstract}

\footnotetext{
S. Zilincik (ه)

University of Defence, Brno, Czech Republic

e-mail: zilinciks@gmail.com

I. Duyvesteyn

Institute of History, Leiden University, Leiden, The Netherlands

e-mail: i.g.b.m.duijvesteijn@hum.leidenuniv.nl

(C) The Author(s) 2021

F. Osinga and T. Sweijs (eds.), NL ARMS Netherlands Annual Review

of Military Studies 2020, NL ARMS, https://doi.org/10.1007/978-94-6265-419-8_24
} 
develop a dynamic and interactive emotion-centric model of deterrence to explain where and how emotions play a role in such a mechanism. We combine the methods of theoretical analysis and literature review to achieve these aims. Our findings indicate that emotions give a new meaning to deterrence by changing the nature of the theory and by highlighting problems of practice. More specifically, scholars should reconsider both the means and the ends of deterrence. Practitioners should be aware that deterrence efforts are hard to sustain and may produce emotional effects detrimental to their original purpose.

Keywords emotions $\cdot$ deterrence $\cdot$ psychology $\cdot$ perception $\cdot$ decision-making • fear $\cdot$ anger $\cdot$ happiness

\subsection{Introduction}

While traditionally seen as strategy, deterrence is, more than anything, a psychological mechanism. ${ }^{1}$ Deterrence is commonly known to comprise the practice, the process or the situation in which one actor relies on a prospect of harm to persuade an opponent not to engage in certain specified behaviour. This notion does not do justice to the salience of the adversary's agency in the whole process. It is the adversary who decides the outcome, or, more precisely, the emotions of the adversary.

Recent research on emotions questions the traditional understanding of deterrence. Emotions are not only the consequences of the defender's actions; they emerge through the challenger's interpretation of the situation. ${ }^{2}$ Once triggered, specific emotions affect cognitive processes and action (or inaction) in far more sophisticated ways than has been assumed. ${ }^{3}$ Finally, emotions may spread, affecting both domestic and foreign politics and producing second-order effects unintended by the original deterrent efforts. ${ }^{4}$ In sum, contemporary research on emotions gives a new meaning to the very nature of deterrence.

Emotions overlap with several biological and psychological processes already discussed in the mainstream deterrence literature. Hormones and other neurotransmitters are essential for emotions to emerge and their influence on deterrence has already been explored. ${ }^{5}$ Emotions, in turn, are responsible for different kinds of

\footnotetext{
${ }^{1}$ Payne 2001, p. 30.

${ }^{2}$ Roseman and Smith 2001, p. 3.

${ }^{3}$ Lerner et al. 2015.

${ }^{4}$ Van Kleef and Fischer 2016.

${ }^{5}$ Payne 2011, pp. 401-403.
} 
biases that affect decision-making and judgments. ${ }^{6}$ Indeed, recent research indicates that this applies even to the effects of framing predicted by prospect theory. ${ }^{7}$ Likewise, specific emotions affect perceptions and, therefore, change how the individual sees the world. ${ }^{8}$ Similarly, emotions and stress interact in dynamic ways. ${ }^{9}$ Finally, emotions affect thoughts and beliefs and indirectly shape what some deterrence scholars have labelled "operational codes" of decision-making. ${ }^{10}$ Emotions are the one element that orchestrates all these processes to prepare individuals for the future. ${ }^{11}$ Therefore, by exploring emotions, this contribution aims to enhance our understanding of the psychology behind deterrence.

What do we know and what do we not know about emotions and deterrence? Apart from answering this question, the chapter also develops a dynamic and interactive emotion-centric model of deterrence to explain where and how emotions play a role in the mechanism. The rationale behind these two aims is to develop a tool to examine deterrence from a unique, emotional perspective. The methods to do so include theoretical analysis and a literature review. We understand emotions to be "complex, organized subsystems consisting of thoughts, beliefs, motives, meanings, subjective bodily experiences, and physiological states". ${ }^{12}$ This definition encompasses the relevant components of emotions as identified by various emotion theories. However, the definition itself is rooted in the appraisal theory of emotions, which argues that emotions emerge as a consequence of one's appraisal of reality rather than as a result of a simple interaction with the world. ${ }^{13}$ This is a deliberate choice, because the theory has a decent track-record of success when it comes to studying emotions in social settings. ${ }^{14}$ As such, the appraisal theory of emotions constitutes the best lens available to explore the role of emotion in deterrence.

By dissecting the emotions related to deterrence, the chapter contributes to the academic debate, as well as offering insights for practical decision-making. The academic contribution resides in the interdisciplinary synthesis of psychological research on emotion with social scientific research on deterrence. Additionally, the chapter also contributes to the literature on emotions in international relations and

\footnotetext{
${ }^{6}$ Engelmann and Hare 2018; Jervis et al. 1985.

${ }^{7}$ Druckman and McDermott 2008; Stein 2013, p. 384. For the initial work on prospect theory, see Kahneman et al. 1982.

${ }^{8}$ Stein 2013, pp. 379-81; Zadra and Clore 2011.

${ }^{9}$ Lazarus 1993. For the initial treatments of stress in deterrence literature, see Holsti and George 1975.

${ }^{10}$ Frijda and Mesquita 2000; George 1967.

${ }^{11}$ Scherer 2013; Cosmides and Tooby 2000.

${ }^{12}$ Lazarus 2001, p. 67.

${ }^{13}$ For a comprehensive overview of emotion theories, see Moors 2009.

${ }^{14}$ Halperin 2015; Markwica 2018.
} 
strategic studies in general. ${ }^{15}$ The argument contributes to political and military practice, enabling practitioners to better understand the emotional effects elicited by their (or their adversary's) use of deterrents. This, in turn, may enable states (wo)men to manipulate these effects to their advantage, or at least to negate the emotional effects desired by the adversary.

The following section introduces the main themes of contemporary emotion science and reflects on how these themes have been incorporated into the deterrence literature. Based on this assessment, we then proceed to develop a dynamic emotion-centric model of deterrence. Consequently, we examine its explanatory power by looking a case of the deterrent efforts between the United States and Iran in early 2020. The concluding section summarizes the implications of our argument.

\subsection{Salient Themes of Contemporary Emotion Science as Reflected in Deterrence Literature}

The psychological study of emotions has been flourishing for the last four decades. New techniques, such as magnetic resonance imaging, have enabled experts to study emotions in unprecedented ways. Scientists can now trace emotional reactions across the human brain. As a result, new emotion theories have been developed, transforming our understanding of what emotions are, how they emerge, and what their influence is. The vast pool of all these fascinating propositions far exceeds the scope of this chapter. ${ }^{16}$ We have selected the themes which are particularly relevant for deterrence and organized the literature review around them. The themes include: the emergence of emotions through interpretation, the influence of specific emotions on cognition and action, and the issue of individual emotions within collectives (see Table 24.1). In discussing the themes, we focus mostly on the emotions of fear, anger and happiness. While we also discuss other emotions in passing, we have chosen these three because of their varied and often diverging characteristics as well as their common occurrence in everyday (political) life. Finally, these three emotions are familiar to people across the world, which makes it easier for our readers to relate to them. ${ }^{17}$

\footnotetext{
${ }^{15}$ For a good introduction to emotions in international relations, see Ariffin et al. 2016. For similar efforts in strategic studies, see Payne 2018, 2015.

${ }^{16}$ See for example Keltner et al. 2014.

${ }^{17}$ Izard 2007.
} 
Table 24.1 Characteristics of fear, anger, and happiness

\begin{tabular}{|c|c|c|c|}
\hline Emotion & Situation for emergence & $\begin{array}{l}\text { Impact on } \\
\text { cognition }\end{array}$ & Impact on behaviour \\
\hline Fear & $\begin{array}{l}\text { Appraisal of threat to } \\
\text { one's objectives }\end{array}$ & $\begin{array}{l}\text { - Risk aversion } \\
\text { - Pessimism } \\
\text { - Feeling a } \\
\text { lack of } \\
\text { control } \\
\text { - Feeling } \\
\text { uncertainty } \\
\text { - Expecting } \\
\text { high effort to } \\
\text { improve the } \\
\text { situation }\end{array}$ & $\begin{array}{l}\text { Motivates freeze, flight, and } \\
\text { fight responses }\end{array}$ \\
\hline Anger & $\begin{array}{l}\text { Appraisal of access to } \\
\text { one's objectives being } \\
\text { blocked by the specific } \\
\text { other }\end{array}$ & $\begin{array}{l}\text { - Risk } \\
\text { acceptance } \\
\text { - Optimism } \\
\text { - Feeling in } \\
\text { control of the } \\
\text { situation } \\
\text { - Feeling } \\
\text { certain about } \\
\text { the situation } \\
\text { - Expecting } \\
\text { high effort to } \\
\text { improve the } \\
\text { situation }\end{array}$ & Motivates punishment of others \\
\hline Happiness & $\begin{array}{l}\text { Appraisal of successful } \\
\text { access to one's } \\
\text { objectives }\end{array}$ & $\begin{array}{l}\text { - Risk } \\
\text { acceptance } \\
\text { - Optimism } \\
\text { - Feeling in } \\
\text { control of the } \\
\text { situation } \\
\text { - Feeling } \\
\text { certain about } \\
\text { the situation } \\
\text { - Expecting } \\
\text { low effort to } \\
\text { improve the } \\
\text { situation }\end{array}$ & $\begin{array}{l}\text { Motivates the continuation of } \\
\text { the activity or its termination } \\
\text { (depends on whether the goals } \\
\text { have already been achieved or } \\
\text { not) }\end{array}$ \\
\hline
\end{tabular}

We derived the data included in this Table from Druckman and McDermott 2008; Lerner and Keltner 2000; Lerner and Tiedens 2006; Smith and Ellsworth 1985; Turowski, Man, and Cunningham 2014 


\subsection{Emotions and Interpretation}

Emotions do not "just happen" to us, nor do deterrent efforts produce the desired emotions automatically. It is a person's interpretation of the situation that determines if emotions emerge and what shape they take. ${ }^{18}$ First, the situation has to be appraised as relevant. ${ }^{19}$ People do not experience emotions about issues they do not care about. Furthermore, the character of the ensuing emotion depends on the meaning we derive from the situation. ${ }^{20}$ Fear, for example, is likely to appear when an individual feels access to their objectives threatened, anger when the access to their objectives is blocked, and happiness when one feels unrestricted access to their objectives. ${ }^{21}$ Deterrent efforts can elicit any of these emotions, as well as others, but the conversion between deterrence threats and emotions is subjective, unstable and non-linear.

Deterrence scholars have progressed considerably in their understanding of how emotions emerge. Early experts considered the link between actions and emotions to be straightforward: the defender would mount a threat and the challenger would subsequently be frightened. ${ }^{22}$ There was little room reserved for interpretation. This (mis)understanding changed with the third wave of deterrence scholarship. Scholars such as Robert Jervis, Richard Lebow and Janice Gross Stein found that the challenger often failed to care enough or that he/she interpreted the "threats" in different ways than the defender intended. ${ }^{23}$ As Lebow points out, threats may be interpreted as provocations and, therefore, trigger anger instead of fear. ${ }^{24}$ Some of the recent works on deterrence have started to emphasize interpretation as the key to emotion elicitation. Robin Markwica's Emotion Choices is a good example, since the author specifically relied on the appraisal theory of emotions to make his argument. $^{25}$ Though not yet mainstream knowledge, the role of interpretation in deterrence practice has started to be taken seriously in recent years.

However, there is a lot more we do not know. The emergence of specific emotions on the side of the defender deserves more attention. Psychological states of defenders are rarely examined in deterrence scholarship. ${ }^{26}$ At the same time, a defender's emotions constitute the engine for the whole deterrence process. Successful deterrent efforts may make the defender happy while ignored one may

\footnotetext{
${ }^{18}$ Moors 2013.

${ }^{19}$ Frijda and Mesquita 2000.

${ }^{20}$ Lazarus 2001.

${ }^{21}$ Smith and Ellsworth 1985.

${ }^{22}$ Herman Kahn, for example, emphasized that deterrents should be "frightening", as if that quality, like all the others he lists, depended on the inherent nature of the tool rather than on the interpretation of the adversary. See the table in Kahn 1961, p. 146.

${ }^{23}$ Jervis et al. 1985. See also Payne 2001, p. 31.

${ }^{24}$ Lebow 2008, p. 552.

${ }^{25}$ Markwica 2018.

${ }^{26}$ For a small set of exceptions, see Jervis et al. 1985.
} 
make him frightened or angry. As the following section will show, the difference between the specific emotion experienced may contribute to the maintenance or to the termination of deterrent efforts. The focus on the defender's emotions is also important because emotions associated with deterrent efforts may gradually lead to institutional changes at the home front. ${ }^{27}$ It is, therefore, necessary to know how deterrence activity affects the emotions of those who conduct it so as to minimize deterrence failures and unwanted institutional transformation.

\subsection{Emotions and Influence}

Specific emotions are unequal in their influence on deterrent efforts. Emotions, both those experienced and sometimes even those merely anticipated, influence cognition and behaviour in diverse ways. Psychological research is now clear that the differences go beyond the simple distinction between positive and negative emotions. ${ }^{28}$ Anger, for example, is a negative emotion, like fear. However, while fear tends to make people more risk-averse and pessimistic, anger tends to make people feel risk-prone and optimistic. ${ }^{29}$ In this respect, anger resembles positive emotions more, such as happiness. ${ }^{30}$ Furthermore, the behavioural influence of emotions varies with context. Fear, for example, can motivate freezing, fleeing, or fighting. ${ }^{31}$ Happiness may motivate both the relaxation of efforts and their pursuit, depending on whether the emotion is experienced or merely anticipated in the future. ${ }^{32}$ Nonetheless, the research also shows that all emotions may provide a basis for rational-decision making and action if their experience is appropriate to the character of the situation. ${ }^{33}$ Indeed, emotions are essential to take any decision, rational or not. ${ }^{34}$ This is because emotions make us care about the consequences of our actions, which in turn enable us to choose from competing objectives in any given context. $^{35}$ The varied and sometimes contradictory influence of specific emotions makes deterrence efforts a real gamble. The odds for deterrence success may be improved by educated anticipation but not by reliable prediction.

Deterrence scholarship has progressed gradually in its understanding of emotional influence. Early deterrence scholars viewed emotions as mere adjuncts to rational calculation, without appreciating the variance in influence. Fear, for

\footnotetext{
${ }^{27}$ Lupovici 2018; Sauer 2015.

${ }^{28}$ Angie et al. 2011; Druckman and McDermott 2008; Lerner and Keltner 2000.

${ }^{29}$ Keltner and Lerner 2001.

${ }^{30}$ Lerner and Tiedens 2006.

${ }^{31}$ Steimer 2002.

${ }^{32}$ Turowski et al. 2014.

${ }^{33}$ Hacker 2018, pp. 71-77.

${ }^{34}$ Phelps et al. 2014.

${ }^{35}$ Damasio 2005.
} 
example, was the only emotion discussed but its variable influence on behaviour was not appreciated. ${ }^{36}$ It is plausible that these early scholars did not consider fear to be a real emotion. ${ }^{37}$ Rather it was "something merely mentioned in passing, definitely not a thing to be dealt with analytically and in its own right". ${ }^{38}$ The central assumption of initial deterrence theorists was that the defender was to use a threat of force to elicit fear, and then to rely on the rational calculation of the opponent to submit to the former's will. ${ }^{39}$ This assumption would only be valid if fear had no influence on cognition or if it always enhanced rationality in the same ways. ${ }^{40}$ These conditions, however, did not correspond to reality. Early deterrence experts thus believed in a psychological mechanism, which in light of today's psychological science would be untenable.

This faulty understanding has been gradually corrected from the third wave of deterrence research onward. A group of scholars in this tradition employed insights from psychological sciences to point out how emotions (through motivated biases) impede rational calculation. ${ }^{41}$ This recognition was important progress, as it provided a basis for more elaborate treatments of the role of emotions. In this vein, Crawford, Lebow, and Stein acknowledged that fear may have a diverging influence in different contexts. ${ }^{42}$ Some recent works have broadened the scope of the investigation to include emotions beyond fear, such as disappointment, shame, humiliation, anger or empathy. ${ }^{43}$ Markwica went even further, as he empirically tested the influence of five different emotions (fear, anger, pride, hope, humiliation) with mixed valence. His research showed that emotions, such as fear and humiliation, can lead the target of deterrence to back down or to resist depending on the context. ${ }^{44}$ Recent works have also acknowledged that specific emotions do not necessarily impede rationality but that they can contribute to it. ${ }^{45}$ Overall, this strand of scholarship demonstrates considerable progress in our understanding of the emotional complexity associated with deterrence.

Similar progress relates to emotional anticipation and its relationship with deterrence. In a crude sense, the anticipation of an emotion has always been part of deterrence theory. It is the anticipated causal link between threat and fear which constitutes the theory of victory in traditional deterrence literature. ${ }^{46}$ Recent

\footnotetext{
${ }^{36}$ Schelling 1966, p. 36.

${ }^{37}$ Crawford 2000, pp. 145-146.

${ }^{38}$ Sauer 2015, p. 111.

${ }^{39}$ Crawford 2013, p. 121.

${ }^{40}$ Even some four decades ago, Patrick Morgan found the assumption puzzling, see Morgan 1983, pp. 21-22; Crawford 2000, pp. 146-147.

${ }^{41}$ Jervis 1976; Jervis et al. 1985; Lebow and Stein 1989.

${ }^{42}$ Crawford 2000, 148; Lebow 2008, 91; Stein and Lotan 2019, pp. 70-71.

${ }^{43}$ Stein 2012, 57; Crawford 2014, pp. 545-546.

${ }^{44}$ Markwica 2018, 17-18.

${ }^{45}$ Markwica 2018, 66-67; Mercer 2005, 2010; Stein 2012, 2013; Thayer 2007, 316-318.

${ }^{46}$ Schelling 2008, $x$.
} 
research has explored the anticipation of emotions beyond fear. For example, several scholars have argued that the anticipation of hatred and anger form the basis of credibility in deterrence by punishment. ${ }^{47}$ The challenger may abstain from the attack if he/she anticipates that the adversary will retaliate so as to feel the pleasantness of revenge. ${ }^{48}$ From a different perspective, Thomas Dolan argues that it is the anticipation of future negative emotions such as shame, guilt and anger that discourages challengers from violating taboos. ${ }^{49}$ Emotional anticipation, though more complicated than often assumed, is at the heart of both deterrence theory and practice.

We still need to know more about other emotions and their relationship to deterrence. Even the more conservative emotion theorists now acknowledge the existence of more than twenty unique emotional states. ${ }^{50}$ For instance, we know little about happiness, joy, interest, curiosity, disgust, regret, grief, hatred or guilt. The influence of some emotions may be beneficial to deterrent efforts, while the influence of others is likely to be detrimental. Happiness is particularly interesting because of its ambiguous influence on motivation. It is far from clear whether the use of inducements, as some experts advise, to make the adversary happy is a reliable recipe for deterrence success. Happy adversaries may easily grow confident and risk-prone, which is not always beneficial for the defender. What is clear is that deterrence theory needs to acknowledge the differences in influence of specific emotions. Without the ability to comprehend all the emotional variations, deterrence practitioners risk the possibility of creating effects which may undermine their own efforts.

\subsection{Emotions in Collectives}

Deterrence aims at individuals but it may ignite emotions in whole societies. Members of smaller groups can experience similar emotions when they interact with each other. Sharing emotions with others is contagious, as humans are good at copying each other's emotional expressions. ${ }^{51}$ However, even members of large collectives can experience similar emotions. This can occur through shared appraisals rooted in collective identity but also through top-down emotional transmission from the political elites to the rest of the society. ${ }^{52}$ Collective feelings of happiness are common after a national sport team achieves success, while collective anger and fear often follow terrorist attacks. ${ }^{53}$ Importantly, the emergence,

\footnotetext{
${ }^{47}$ Löwenheim and Heimann 2008; McDermott et al. 2017; Jervis 2017, p. 1xxi.

${ }^{48}$ McDermott et al. 2017, p. 71.

${ }^{49}$ Dolan 2013, pp. 42-43.

${ }^{50}$ Keltner 2019.

${ }^{51}$ Van Kleef and Fischer 2016, 7-8.

${ }^{52}$ Van Kleef and Fischer 2016, p. 6; Hall and Ross 2019, pp. 1360-1363.

${ }^{53}$ Hall and Ross 2015.
} 
experience and expression of some emotions varies across cultures. ${ }^{54}$ It follows that deterrent efforts may produce a variety of emotions, that can further transform the political landscapes of whole societies and this transformation may be influenced by cultural specifics.

Deterrence scholarship has made great progress in its understanding of emotions in collectives. The first-generation scholars of deterrence research assumed states to be unitary actors, with no difference between individual and collective emotions. ${ }^{55}$ Recent deterrence research on collective emotions deals predominantly with so-called incidental emotions. These are the emotions present in collectives before the deterrence efforts take place and they influence the emergence of subsequent emotions. ${ }^{56}$ Crawford and Lebow, for example, have both argued that the institutions of some polities may be inherently rooted in fear and this emotion then influences responses to deterrence. ${ }^{57}$ Amir Lupovici argues that this kind of emotional institutionalization may lead defenders to tie their identity to deterrent efforts that protect them from the experience of undesired emotions. ${ }^{58}$ Stein, drawing attention to the variance in strategic cultures, has argued that political elites from the so-called "honour" cultures may experience different emotions than Western thinkers assume. ${ }^{59}$ Collective emotions in their incidental forms have been explored on both sides of the deterrence relationship.

Still, we know little about the interaction between collective emotions and strategic cultures. Since the emergence and the experience of emotions differs across cultures, this gives a whole new meaning to the idea of tailored deterrence. It means that eliciting particular collective emotions may be impossible in some strategic cultures or that the experience itself may vary considerably. It is therefore essential to know the peculiarities of specific strategic cultures to increase the chances of successful emotional manipulation by deterrence.

\subsection{The Emotion-Centric Model of Deterrence}

So far we have only discussed emotions in a static manner; now is the time to make them dynamic. Accordingly, we present a model (see Fig. 24.1) which explains where and how emotions play a role as related to the deterrence mechanism. The model brings together all the themes discussed in the previous sections. In

\footnotetext{
${ }^{54}$ Barrett 2017, pp. 145-150. For more details, see Fontaine et al. 2013, ch 20-26.

${ }^{55}$ Achen and Snidal 1989, p. 150.

${ }^{56}$ Renshon and Lerner 2012, pp. 1-2.

${ }^{57}$ Crawford 2009, 2013; Lebow 2008, pp. 89-92.

${ }^{58}$ Lupovici 2018, pp. 6, 65-69.

${ }^{59}$ Stein 2012, pp. 60.
} 


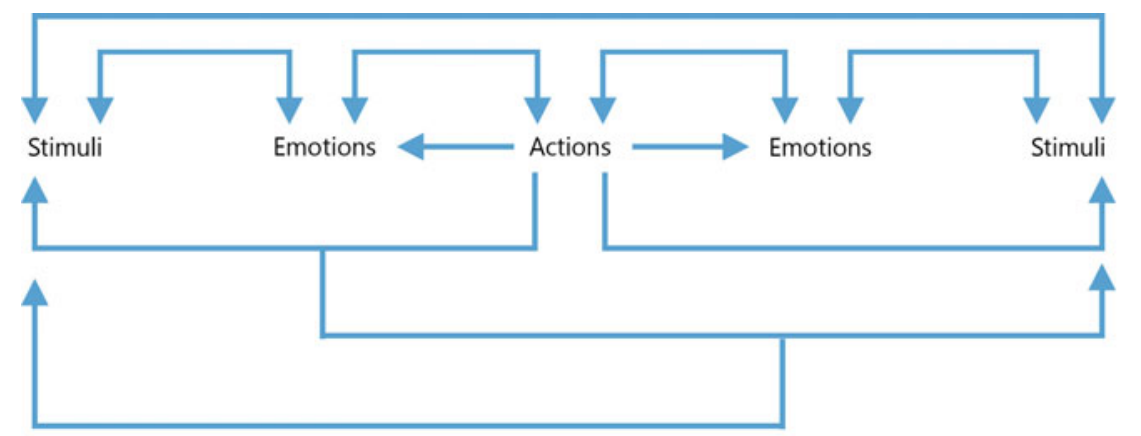

Fig. 24.1 Interactive and dynamic model of emotions and deterrence (Source The authors)

constructing the model, we have been inspired by similar models on emotions already developed by social scientists. ${ }^{60}$ We argue that the model is necessary to understand the psychological factors of deterrence, but it is not sufficient-those seeking a holistic psychological understanding of deterrence should combine the model with other works on deterrence psychology. ${ }^{61}$ The model is emotion-centric in nature; it pays attention to emotions at the expense of other psychological considerations to emphasize their importance. ${ }^{62}$

The model is circular rather than linear. Emotions, rooted in either domestic or political concerns, play a role even before the deterrent activity takes place. Depending on the specific emotions, the defender either chooses to launch the deterrent activity or to abstain from it. On the other side of the equation, the same motivational force of emotions influences the challenger's decision to attack. Simultaneously, both defender and challenger can be (de)motivated to act by their own anticipation of the adversary's emotions or by the adversary's expressions of emotions. The next step is the deterrence itself and the emotions it triggers on the side of defender, challenger, and potential observers. This is further complicated by the fact that few of these actors are emotionally unitary. On the contrary, different segments of populations within one polity are likely to draw diverse interpretations, based on their own biases, prejudices, opinions, desires, memories, perceptions, and incidental emotions. The emotions and their anticipation influence the further thoughts and actions of all affected actors. Emotions, therefore, complete a full circle from being an initial motivation, to being transformed through interpretation, to again being the driving force of thought and action. Thus, though emotions may change over time, they never stop being a relevant factor in the deterrence mechanism.

\footnotetext{
${ }^{60}$ Halperin 2015; Lerner et al. 2015; Markwica 2018.

${ }^{61}$ See for example Payne 2001, pp. 104-14.

${ }^{62}$ Roy 2016.
} 
We now turn to explore this model further by looking at case material; the highly volatile relationship between the United States and Iran, which experienced a severe crisis in January 2020.

\subsection{US-Iran Case Study}

On 3 January 2020, the leader of the Iranian Revolutionary Guard Quds Force Qasim Suleimani was killed by a Hellfire missile fired from an American drone. ${ }^{63}$ The killing of Suleimani has been justified by the United States' government as a significant reinforcement of deterrence: 'This strike was aimed at deterring future Iranian attack plans. The United States will continue to take all necessary action to protect our people and our interests wherever they are around the world' ${ }^{64}$ This assertion is consistent with observations of other experts. ${ }^{65}$ We therefore use this case to illustrate where, when and how emotions played a role in the deterrence mechanism. Our focus is on a small set of the most common emotions (fear, anger, happiness) that have surfaced in the notable analyses of the case. The analysis explores the role of these emotions in the two phases delineated in the model above. To identify the presence of specific emotions we reviewed journalistic and professional commentaries of the event. In terms of coding, we searched for particular emotion words as well as words from the associated emotion families-not only fear but also worries, anxiety, horror, et cetera. Additionally, we used the characteristics of specific emotions to infer their presence by the appearance of the relevant stimuli, as well as to explain how particular emotions may have contributed to the specific choices and demonstrated behaviours. While we primarily focus on emotions within the US and Iran, the main actors in the confrontation, collateral emotions of others are also discussed.

\subsubsection{Phase 1: Emotions before Deterrence}

Anger (along with hatred) was certainly present in the American administration and security services. Many members of these collectives considered Suleimani responsible for American soldiers being killed during the Iraq War. ${ }^{66}$ The American political establishment was also angry that, despite the stringent sanctions regime, Iran had been able to increase and strengthen its position in the region, in its quest for regional hegemony. Conversely, the US had been losing allies and influence in

\footnotetext{
${ }^{63} \mathrm{Al}$ Jazeera 2020b.

${ }^{64}$ Department of Defense 2020.

${ }^{65}$ Seligman 2020.

${ }^{66}$ Jervis 2020.
} 
the Middle East, partly by choice, e.g. withdrawal from northern Syria. It had fewer friends and more enemies, and their 'recourse to brute force is always a sign of lost legitimacy and authority'. ${ }^{67}$ Anger at Iranian responsibility for American losses may have motivated the US president to use violence to remove Suleimani without regard for long-term consequences.

Stimuli for fear were also abundant. Before the attack against Suleimani, American credibility was perceived as being at stake. A whole series of attacks against American targets had gone unanswered. ${ }^{68}$ In an interview with Foreign Policy, General David Petraeus elaborated on the weak American deterrent position: 'Many people had rightly questioned whether American deterrence had eroded somewhat because of the relatively insignificant responses to the earlier actions' ${ }^{69}$ In an analysis in the New Statesmen, Lawrence Freedman argued along similar lines, 'Iranians shooting down an American drone over the Strait of Hormuz in June 2019, and allegedly attacking a Saudi Aramco oil facility later that year; Trump refused to authorize retaliatory airstrikes. So tepid was his response that Tehran was emboldened - they saw Trump as something of a paper tiger, big on boasts but short on action'. ${ }^{70}$ Another source of American fear may have been a perceived danger of imminent attack. ${ }^{71}$ Attacks against the American compounds in Iraq had directly preceded the drone strike. Furthermore, the president in his public justification for the murder, mentioned intelligence reports, later retracted, of imminent threats. Fear could have motivated Trump to fight and fortify the US position.

Stimuli for happiness were also present. The establishment saw great luck in being given the opportunity to kill Suleimani. In a Hoover Institute speech, the secretary of state, Mike Pompeo, claimed that 'had we not taken that strike against Qasem Soleimani, our leadership - the recommendation that we made to President Trump - we would have been "culpably negligent" had we not made that recommendation, imposed a significant cost on the regime for their bad decision'. ${ }^{72}$ Simultaneously, the administration also probably, and not unreasonably, anticipated large parts of the US domestic public to feel happy after hearing about the general's death. Happiness elicited in such a way could have motivated them to pursue their plan as the successful achievement of their objectives seemed at hand.

In Iran, fear was commonplace. The US policies in the region were often interpreted as threatening and dangerous. ${ }^{73}$ The sanctions had started to hurt, and two days before the attack on 1 January, the Iranian president had gone on national

\footnotetext{
${ }^{67}$ Mishra 2020.

${ }^{68} \mathrm{Al}$ Jazeera 2020b.

${ }^{69}$ Seligman 2020.

${ }^{70}$ Freedman 2020.

${ }^{71}$ Riley-Smith 2020.

${ }^{72}$ Pompeo 2020.

${ }^{73}$ Strobel et al. 2019.
} 
television to state as much. ${ }^{74}$ Moreover, there were probably fears about the stability of the regime. People had started taking to the streets in Iraq and Lebanon to demonstrate against Iranian influence, e.g., the attacks against the Iranian consulates in Najaf and Karbala. ${ }^{75}$ In Iran, people had been protesting in the preceding months against rising prices for petrol. ${ }^{76}$ Fears of domestic and foreign threats produced a powerful incidental emotion on the side of the regime.

\subsubsection{Phase 2: Deterrence and the Emergence of Emotions}

The attack elicited a kaleidoscopic range of emotions across the world. These, of course, depended upon the individual's and group's interpretations of the situation. Furthermore, states experienced no emotional unity in the aftermath. In the US context, some conservatives saw the drone strike as a legitimate act of defence and revenge, and thus felt happy afterward. ${ }^{77}$ Pompeo expressed himself confidently: 'We now enjoy a great position of strength regarding Iran. It's as good as it has ever been, and Iran has never been in the place that it is today. ${ }^{78}$ Democrats had already despised Trump before the attack; it is understandable that they interpreted the activity unfavourably and felt angry. ${ }^{79}$ Seeing the assassination as a dangerous precedent, some commentators felt fear as they anticipated the anger of the Iranians. $^{80}$

In Iran, thousands felt angry, for they interpreted the attack as an act of American malevolence and an obstacle to their security. ${ }^{81}$ The supreme leader Ayatollah Khamenei said in a statement that 'harsh revenge' would be enacted against the United States for killing Suleimani. ${ }^{82}$ Furthermore, public demonstrations showed a measure of anger among the Iranian public. ${ }^{83}$ However, the regime was at the same time scared of further escalation, and rightly so. Military conflict with the US would be devastating for the already fragile polity. The evidence of fear is also implied by the relatively harmless way in which Iran chose to respond: an attack against American installations in Iran without causing any casualties, which is a clear effort

\footnotetext{
${ }^{74}$ The speech by President Rouhani is available in Asharq Al-Awsat 2020. See also the commentary by Goldman 2020.

${ }^{75}$ Reimer 2020.

${ }^{76}$ Johnson 2019.

${ }^{77}$ Associated Press 2020.

${ }^{78}$ Seligman and Gramer 2020.

${ }^{79}$ Associated Press 2020; Risen 2020; Rove 2020.

${ }^{80}$ Ward 2020.

${ }^{81}$ Knights 2020.

${ }^{82} \mathrm{Al}$ Jazeera 2020a.

${ }^{83}$ Naji 2020.
} 
to de-escalate. ${ }^{84}$ Furthermore, it may be that some individuals and groups were happy. After all, the US attack enhanced the cohesion of Iranian society after the weeks of unrest. ${ }^{85}$ The regime might interpret this as a successful development in accordance with its goals and experience happiness in the aftermath.

Then there were collateral emotions experienced by many others. Some Syrians and Iraqis felt happy, as they celebrated the death of their long-time enemy. ${ }^{86}$ Many in Europe felt scared because of the appraised threat of further escalation of violence. ${ }^{87}$ Instead of being confined to their original locations, many of these emotions and their anticipations spread rapidly throughout the world via social media.

\subsection{Conclusion}

We started the chapter by observing that emotions give meaning to practically everything. Our review indicates that emotions may well give new meaning to deterrence itself. They alter our understanding of deterrence in three ways. First, emotions form the essence of deterrence. Other psychological processes, such as perception, attention, judgment, memory, or thought, are less relevant, if emotions are not taken into account. This is not to say that these cognitive processes are less important, but emotions are the one element that synchronizes all of them so as to prepare individuals to face the challenges of the present and the future. Any examination of deterrence, in theory and in practice, needs to start from an emotion-centric perspective and then move to add other psychological elements. The model we have developed in this chapter may be refined as new insights about emotions are revealed, but it could be a stepping stone for psychological understandings of deterrent efforts and their consequences.

Second, emotions give a new meaning to the content of both means and ends in deterrence theory. The fundamental causal mechanism behind deterrence, the issuing of threats to produce fear, requires refinement. Threats, even if perfectly signalled, attributed and credible, need to be interpreted as relevant and as threats. Otherwise, they do not elicit emotions at all or they may elicit ones that are detrimental to the whole effort. To alleviate the problem, we may incorporate the actual use of violence into existing deterrence theory, as illustrated by our case study and Chap. 14 by Eitan Shamir in this volume. Of course, even the use of violence is open to interpretation. However, space for interpretation is inherently smaller compared to verbal threats or positioning of weapon systems. Additionally, deterrence theory needs to expand its psychological content. Emotions other than

\footnotetext{
${ }^{84}$ The regime responded by first warning and then attacking American positions in Iraq but no casualties occurred in the aftermath. See BBC 2020.

${ }^{85}$ Esfandiary 2020; Mishra 2020.

${ }^{86}$ Hamid 2020.

${ }^{87}$ Wintour 2020.
} 
fear may be useful for deterrent purposes. It may be that conceptual content will be enhanced gradually as more emotions prove useful for deterrent purposes. Eventually, this content expansion may in turn necessitate the re-examination of the means by which the emotional effects are to be accomplished. In short, the incorporation of varied emotions may transform the very nature of deterrence theory.

Third, deterrence practice is more complex than usually assumed. Above all, the insights from emotion sciences indicate that we have little control over emotions and, therefore, cognition and behaviour of others. Furthermore, actors from some strategic cultures may be undeterrable simply because they cannot experience the intended emotions or because they experience them differently. The tailoring of deterrence efforts to particular adversaries needs to include an assessment of the latter's emotional profiles, histories and cultures. Then there is the problem of collateral emotions. Deterrence is never an isolated act. It affects the domestic and foreign politics of direct participants and observers alike. Or, to put it in more strategically pleasing jargon, deterrence is just a continuation of emotional life with the admixture of violent means. Some of the collective emotions are beneficial, others detrimental. Deterrence practice needs to incorporate anticipation of these emotional effects so as to enable their countering. Otherwise, the failures of deterrence may not only lead to the adversary's attacks but also to the transformation of the defender's own institutions. In sum, deterrence practice is much more about the diverse nature of emotions than about simple cost/benefit calculations.

\section{References}

Achen C H H, Snidal D (1989) Rational Deterrence Theory and Comparative Case Studies. World Politics 41:143-169

Al Jazeera (2020a) Iran in Mourning, Vows Revenge for Qassem Soleimani's Killing. https:// www.aljazeera.com/news/2020/01/iran-mourning-vows-revenge-qassem-soleimani-killing200103100607193.html. Accessed 30 May 2020

Al Jazeera (2020b) US-Iran Tensions; Timeline of Events Leading to the Soleimani Killing. https://www.aljazeera.com/news/2020/01/iran-tensions-timeline-events-leading-soleimanikilling-200103152234464.html. Accessed 30 May 2020

Angie A D, Connelly S, Waples E P, Kligyte V (2011) The Influence of Discrete Emotions on Judgement and Decision-Making: A Metaanalytic Review. Cognition and Emotion 25:13931422

Ariffin Y, Coicaud J M, Popovski V (2016) Emotions in International Politics. Cambridge University Press, New York

Asharq A A (2020) Iran President: US Sanctions Cost Country \$200 Billion. https://aawsat.com/ english/home/article/2061761/iran-president-us-sanctions-cost-country-200-billion. Accessed 30 May 2020

Associated Press (2020) Here's How 2020 Democrats Are Reacting to the U.S. Assassination of Iran's Qasem Soleimani. https://time.com/5758264/qasem-soleimani-2020-democrat-reaction/. Accessed 30 May 2020

Barrett L F (2017) How Emotions Are Made. Houghton Mifflin Harcourt, New York

BBC (2020) 'Iran Missile Attack: Did Tehran Intentionally Avoid US Casualties?' BBC, 8 January 2020. https://www.bbc.com/news/world-middle-east-51042156. Accessed 30 May 2020 
Cosmides L, Tooby J (2000) Evolutionary Psychology and the Emotions. In: Lewis M, Haviland-Jones J M (eds) Handbook of Emotions. The Guilford Press, New York, 91-115

Crawford N (2000) The Passion of World Politics: Propositions on Emotion and Emotional Relationships. International Security 24:116-156

Crawford N (2009) Human Nature and World Politics: Rethinking "Man". International Relations 23:280-82

Crawford N (2013) Emotions and International Security: Cave! Hic Libido. Critical Studies on Security $1: 121-23$

Crawford N (2014) Institutionalizing Passion in World Politics: Fear and Empathy. International Theory 6:535-57

Damasio A (2005) Descartes' Error: Emotion, Reason, and the Human Brain. Penguin Books, New York

De Waal F (2019) Mama's Last Hug: Animal Emotions and What They Tell Us about Ourselves. Norton and Company, New York

Department of Defense (2020) Statement by the Department of Defense. https://www.defense.gov/ Newsroom/Releases/Release/Article/2049534/statement-by-the-department-of-defense/.

Accessed 30 May 2020

Dolan T M (2013) Unthinkable and Tragic: The Psychology of Weapons Taboos in War. International Organization 67:37-63

Druckman J N, McDermott R (2008) Emotion and the Framing of Risky Choice. Political Behaviour 30:297-321

Engelmann J B, Hare T A (2018) Emotions Can Bias Decision-Making Processes by Promoting Specific Behavioural Tendencies. In: Fox et al (eds) The Nature of Emotion: Fundamental Questions. Oxford University Press, New York, 355-359

Esfandiary D (2020) By Killing Qassem Suleimani Trump Has Achieved the Impossible, Uniting Iran https://www.theguardian.com/commentisfree/2020/jan/07/qassem-suleimani-trumpuniting-iran-assassination-government. Accessed 30 May 2020

Fontaine J J R, Scherer K J, Soriano C (2013) Components of Emotional Meaning: A Sourcebook. Oxford University Press, Oxford

Freedman L (2020) Death of a Warlord. https://www.newstatesman.com/world/middle-east/2020/ 01/death-warlord. Accessed 30 May 2020

Frijda N, Mesquita B (2000) Beliefs Through Emotions. In: Frijda N, Manstead A, Bem S (eds) Emotions and Beliefs: How Feelings Influence Thoughts. Cambridge University Press, Cambridge, 45-64

George A (1967) The "Operational Code": A Neglected Approach to the Study of Political Leaders and Decision-Making. RAND Corporation, Santa Monica

Goldman D P (2020) How Fragile Is Iran's Regime? https://www.asiatimes.com/2020/01/article/ how-fragile-is-irans-regime-2/. Accessed 30 May 2020

Hacker P M S (2018) The Passions: A Study of Human Nature. Blackwell, Oxford

Hall T H, Ross A A G (2015) Affective Politics after 9/11. International Organization 69:847-879

Hall T H, Ross A A G (2019) Rethinking Affective Experience and Popular Emotion: World War I and the Construction of Group Emotion in International Relations. Political Psychology 40:1357-1372

Halperin E (2015) Emotions in Conflict: Inhibitors and Facilitators of Peace Making. Routledge, New York

Hamid S (2020) American Self-Criticism Borders on Narcissism. https://www.theatlantic.com/ ideas/archive/2020/01/the-us-isnt-as-important-as-the-left-thinks/604642/. Accessed 30 May 2020

Holsti O R, George A (1975) The Effects of Stress on the Performance of Foreign Policymakers. In: Cotter C P (ed) Political Science Annual. Bobbs-Merrill, Indianapolis, 255-319

Izard C E (2007) Basic Emotions, Natural Kinds, Emotion Schemas, and a New Paradigm. Perspectives on Psychological Science 2:260-280

Jervis R (1976) Perception and Misperception in International Politics. Princeton University Press, Princeton 
Jervis R (2017) Perception and Misperception in International Politics. Princeton University Press, Princeton

Jervis R (2020) On the Current Confrontation with Iran https://warontherocks.com/2020/01/onthe-current-confrontation-with-iran/?fbclid=IwAR0-

feIZoilnsBYwKzMWfAYpKnMPSV0w3i6xheYzSupd0FDsZTFP6mtH5Ro. Accessed 30 May 2020

Jervis R, Lebow R N, Stein J G (1985) Psychology and Deterrence. The John Hopkins University Press, Baltimore

Johnson K (2019) Iran Protests Suggest Trump Sanctions Are Inflicting Serious Pain https:// foreignpolicy.com/2019/11/20/iran-protests-trump-sanctions-inflicting-serious-pain/. Accessed 30 May 2020

Kahn H (1961) On Thermonuclear War. Princeton University Press, Princeton

Kahneman D, Slovic P, Amos T (1982) Judgment under Uncertainty: Heuristics and Biases. Cambridge University Press, Cambridge

Keltner D (2019) Toward a Consensual Taxonomy of Emotions. Cognition and Emotion 33:14-19

Keltner D, Lerner J (2001) Fear, Anger and Risk. Journal of Personal and Social Psychology 81.1:146-159

Keltner D, Oatley K, Jenkins J M (2014) Understanding Emotions. Wiley, Hoboken

Knights M (2020) Why Iran May Not Be Satisfied with a "Slap" at Trump. https://foreignpolicy. com/2020/01/07/qassem-suleimani-iran-killing-next-move/. Accessed 30 May 2020

Lazarus R (1993) From Psychological Stress to the Emotions: A History of Changing Outlooks. Annual Review of Psychology 44:1-21

Lazarus R (2001) Relational Meaning and Discrete Emotions. In: Scherer K R, Schorr A, Johnstone T (eds) Appraisal Process in Emotion: Theory, Methods, Research. Oxford University Press, Oxford, 37-67

Lebow R N (2008) A Cultural Theory of International Relations. Cambridge University Press, New York

Lebow R N, Stein JG (1989) Rational Deterrence Theory: I Think, Therefore I Deter. World Politics 41:208-224

Lerner J, Keltner D (2000) Beyond Valence: Toward a Model of Emotion-Specific Influences on Judgement and Choice. Cognition and Emotion 14:473-493

Lerner J, Tiedens L (2006) Portrait of The Angry Decision Maker: How Appraisal Tendencies Shape Anger's Influence on Cognition. Journal of Behavioural Decision Making 19:115-37

Lerner J, Li Y, Valdesolo P, Kassam K S (2015) Emotion and Decision Making. Annual Review of Psychology 66:799-823

Löwenheim O, Heimann G (2008) Revenge in International Politics. Security Studies 17:685-724

Lupovici A (2018) The Power of Deterrence: Emotions, Identity, and America and Israeli Wars of Resolve. Cambridge University Press, Cambridge

Markwica R (2018) Emotional Choices: How the Logic of Affect Shapes Coercive Diplomacy. Oxford University Press, Oxford

McDermott R, Lopez A C, Hatemi P K (2017) "Blunt Not the Heart, Enrage It": The Psychology of Revenge and Deterrence. Psychology of War 1:68-88

Mercer J (2005) Rationality and Psychology in International Politics. International Organization 59:77-106

Mercer J (2010) Emotional Beliefs. International Organization 64:1-31

Mishra P (2020) Hardliners in the U.S. and Iran Are Each Other's Best Friends https://www. bloomberg.com/opinion/articles/2020-01-07/hardliners-in-the-u-s-and-iran-are-each-other-sbest-friend. Accessed 30 May 2020

Moors A (2009) Theories of Emotion Causation: A Review. Cognition and Emotion 23:625-62

Moors A (2013) On the Causal Role of Appraisal in Emotion. Emotion Review 5:132-40

Morgan P M (1983) Deterrence: A Conceptual Analysis. SAGE Publications, Beverly Hills

Naji K (2020) Soleimani: Why Huge Crowds Turned Out for Iran Commander's Funeral https:// www.bbc.com/news/world-middle-east-51021854. Accessed 30 May 2020 
Payne K B (2001) The Fallacies of Cold War Deterrence and a New Direction. The University Press of Kentucky, Lexington

Payne K B (2011) Understanding Deterrence. Comparative Strategy 30:393-427

Payne K (2015) The Psychology of Strategy: Exploring Rationality in the Vietnam War. Hurst and Company, London

Payne K (2018) Strategy, Evolution, and War. Georgetown University Press, Washington

Phelps E A, Lempert K M, Sokol-Hesner P (2014) Emotion and Decision Making: Multiple Modulatory Neural Circuits. Annual Review of Neuroscience 37:263-288

Pompeo M (2020) The Restoration of Deterrence; the Iranian Example https://id.usembassy.gov/ the-restoration-of-deterrence-the-iranian-example/. Accessed 30 May 2020

Reimer J (2020) Iran Claws Back Its Regional Influence. RAND Corporation, Santa Monica

Renshon J, Lerner J (2012) Decision-Making, the Role of Emotions in Foreign Policy. In: Christie D J (ed) The Encyclopedia of Peace Psychology. Blackwell Publishing, Oxford, pp 1-6

Riley-Smith B (2020) US Says Attack Planned by Qassim Soleimani Was “days” from Happening. https://www.telegraph.co.uk/news/2020/01/07/us-says-attack-planned-qassim-soleimani-dayshappening/. Accessed 30 May 2020

Risen J (2020) Donald Trump Murdered Qassim Suleimani. https://theintercept.com/2020/01/09/ donald-trump-iran-suleimani-murder/. Accessed 30 May 2020

Roseman I, Smith C (2001) Appraisal Theory. In: Scherer K R, Schorr A, Johnstone T (eds) Appraisal Process in Emotion: Theory, Methods, Research. Oxford University Press, Oxford, pp 1-20

Rove K (2020) The Politics of Killing Soleimani. https://www.wsj.com/articles/the-politics-ofkilling-soleimani-11578528322. Accessed 30 May 2020

Roy J M (2016) From Intersubjectivity to International Relations: The Relevance of the "Emotive Turn" of Cognitive Science. In: Ariffin Y, Coicaud J M, Popovski V (eds) Emotions in International Politics. Cambridge University Press, New York, pp 80-111

Sauer F (2015) Atomic Anxiety: Deterrence, Taboo and the Non-Use of US Nuclear Weapons. Palgrave Macmilllan, New York

Schelling T C (1966) Arms and Influence. Yale University Press, New Haven

Schelling T C (2008) Arms and Influence. Yale University Press, New Haven

Scherer K J (2013) Measuring the Meaning of Emotion Words: A Domain-Specific Componential Approach. In: Fontaine J J R, Scherer K J, Soriano C (eds) Components of Emotional Meaning: A Sourcebook. Oxford University Press, Oxford, pp 7-30

Seligman L (2020) Petraeus Says Trump May Have Helped "Reestablish Deterrence" by Killing Suleimani. https://foreignpolicy.com/2020/01/03/petraeus-on-qassem-suleimani-killing-saystrump-helped-reestablish-deterrence/. Accessed 30 May 2020

Seligman L, Gramer R (2020) Nervous U.S. Allies Brace for Iran Fallout. https://foreignpolicy. com/2020/01/14/nervous-allies-trump-iran-fallout-middle-east-tensions-suleimani-killingconflict/. Accessed 30 May 2020

Smith C, Ellsworth P (1985) Patterns of Cognitive Appraisal in Emotion. Journal of Personality and Social Psychology 48:813-838

Steimer T (2002) The Biology of Fear- and Anxiety- Related Behaviours. Dialogues in Clinical Neuroscience 4:231-249

Stein J G (2012) Deterring Terrorism, Not Terrorists. In: Wenger A, Wilner A (eds) Deterring Terrorism : Theory and Practice. Stanford University Press, Stanford, pp 46-66

Stein J G (2013) Threat Perception in International Relations. In: Huddy L, Sears D O, Levy J S (eds) The Oxford Handbook of Political Psychology. Oxford University Press, Oxford, pp 364-394

Stein J G, Lotan M (2019) Disabling Deterrence and Preventing War: Decision Making at the End of the Nuclear Chain. In: Harrington A I, Knopf J W (eds) Behavioural Economics and Nuclear Weapons. University of Georgia Press, Athens, pp 56-77 
Strobel W P, Youssef N A, Salama V (2019) Intelligence Suggests U.S., Iran Misread Each Other, Stoking Tensions. https://www.wsj.com/articles/trump-told-aides-he-doesnt-want-war-withiran-11558036762. Accessed 30 May 2020

Thayer B (2007) Thinking about Nuclear Deterrence Theory: Why Evolutionary Psychology Undermines Its Rational Actor Assumptions. Comparative Strategy 26:311-323

Turowski T K, Man V Y, Cunningham W A (2014) Positive Emotion and the Brain: The Neuroscience of Happiness. In: Gruber J, Moskowitz JT (eds) Positive Emotion: Integrating the Light Sides and Dark Sides. Oxford University Press, Oxford, pp 95-115

Van Kleef G A, Fischer A H (2016) Emotional Collectives: How Groups Shape Emotions and Emotions Shape Groups. Cognition and Emotion 30:3-19

Ward A (2020) The US Killed Soleimani. What Will Iran Do Next? https://www.vox.com/2020/1/ 10/21058430/iran-crisis-war-soleimani-response-trump-war. Accessed 30 May 2020

Wintour P (2020) European Leaders Call for De-Escalation of Crisis after Suleimani Killing. https://www.theguardian.com/world/2020/jan/03/qassem-suleimani-killing-may-spell-endiran-nuclear-deal-europe-fears. Accessed 30 May 2020

Zadra J R, Clore G L (2011) Emotion and Perception: The Role of Affective Information. Wiley Interdisciplinary Review of Cognitive Sciences 2:676-685

Samuel Zilincik is a doctoral student of Security and Strategic studies at Masaryk University and a teaching assistant at the University of Defence in the Czech Republic. He also has conducted internships at the Hague Centre for Strategic Studies in the Netherlands), at the Centre for Security and Prevention in the Czech Republic, and at the Strategic Policy Institute in Slovakia.

Isabelle Duyvesteyn is a Professor of International Studies and Global History at the Institute of History at Leiden University in the Netherlands. Prior to joining the History Institute, she held a special chair in Strategic Studies at the Institute of Political Science at Leiden. She has been a member of the National Advisory Council for International Affairs and is a member of the Scientific Advisory Board of the Netherlands Defence Academy.

Open Access This chapter is licensed under the terms of the Creative Commons Attribution 4.0 International License ( http://creativecommons.org/licenses/by/4.0/), which permits use, sharing, adaptation, distribution and reproduction in any medium or format, as long as you give appropriate credit to the original author(s) and the source, provide a link to the Creative Commons license and indicate if changes were made.

The images or other third party material in this chapter are included in the chapter's Creative Commons license, unless indicated otherwise in a credit line to the material. If material is not included in the chapter's Creative Commons license and your intended use is not permitted by statutory regulation or exceeds the permitted use, you will need to obtain permission directly from the copyright holder.

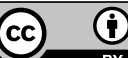

